\title{
Premature birth was not associated with increased body fatness in four-year-old boys and girls
}

Elisabet Forsum, Eva Flinke Carlsson and Elisabeth Olhager

The self-archived postprint version of this journal article is available at Linköping University Institutional Repository (DiVA):

http://urn.kb.se/resolve?urn=urn:nbn:se:liu:diva-161148

N.B.: When citing this work, cite the original publication.

Forsum, E., Flinke Carlsson, E., Olhager, E., (2019), Premature birth was not associated with increased body fatness in four-year-old boys and girls, Acta Paediatrica. https://doi.org/10.1111/apa.14990

Original publication available at:

https://doi.org/10.1111/apa.14990

Copyright: Wiley (12 months)

http://eu.wiley.com/WileyCDA/ 
Premature birth was not associated with increased body fatness in four-year-old boys and girls

Forsum $\mathrm{E}^{1}$, Flinke $\mathrm{E}^{1}$, Olhager $\mathrm{E}^{2}$ and "The body composition study group" 3

${ }^{1}$ Department of Clinical and Experimental Medicine, Linköping University, Linköping, Sweden

${ }^{2}$ Department of Clinical Science, Lund University, Lund, Sweden

${ }^{3}$ Appendix S1

\section{Correspondence}

E Forsum PhD, Department of Clinical and Experimental Medicine, Linköping University, SE

58185 Linköping, Sweden

Tel: +46-10-1034743; +46-70-5233288

Email: elisabet.forsum@liu.se

Short title: Body composition of prematurely born children 


\section{ABSTRACT}

Aim: Premature birth is a worldwide problem and increases the risk of chronic disease later in life. Prematurely born infants may have a high percentage of body fat at term equivalent age, but it is unclear if this characteristic is maintained in childhood. Therefore, we compared the size and body composition of four-year-old prematurely born children to such values of full-term controls.

Methods: Between 2013 and 2015 we assessed weight, height, fat mass and fat-free mass, using air displacement plethysmography in 188 reasonably healthy prematurely born four-year-olds (98 boys).

Results: At four years of age, prematurely born children (gestational weeks at birth: 23.3-36.9) tended to be lighter and shorter and to contain less fat mass and fat-free mass than did full-term controls. The gestational age at birth of the prematurely born children correlated positively and significantly $(\mathrm{p}<0.05)$ with height, weight, body mass index, fat mass $(\mathrm{kg}, \%)$, fat mass index and fat-free mass $(\mathrm{kg})$ in girls but not in boys.

Conclusion: Prematurity was not associated with increased body fatness in our four-year-olds. Our findings are relevant in relation to previously published results showing that premature birth is associated with chronic disease later in life. 


\section{Key notes}

- Premature birth increases the risk of chronic disease later in life and prematurely born infants may have high body fatness, but it is unclear if this is maintained into childhood.

- Prematurity did not increase body fatness in four-year-olds and gestational age at birth correlated with size and fatness in girls.

- These findings are of interest because prematurity is associated with chronic disease later in life.

\section{Key words}

Air displacement plethysmography, body composition, premature birth, four-year-old children

\section{Abbreviations}

BMI, Body mass index; r, Correlation coefficient. 


\section{INTRODUCTION}

Prematurity is a worldwide problem occurring in approximately $10 \%$ of all births (1). It is not only an important cause of death in young children (1), but it can also be linked to increased blood pressure (2-4) and impaired insulin sensitivity (4-7) later in life. This suggests that in adulthood, prematurely born individuals have an increased risk of disorders commonly known as chronic disease, including hypertension, type 2 diabetes mellitus and heart disease. Mechanisms suggested to be responsible for this link between prematurity and chronic disease include nutrition, oxidative stress, epigenetic changes, endocrine and renal changes (3) as well as an unfavorable intrauterine environment and the growth pattern during infancy and childhood $(4,6,7)$ indicating that prematurity influences the risk for chronic disease in a complex way.

Studies demonstrate that prematurely born infants have a high percentage of body fat at term-equivalent age (8-12). These observations have caused concern that such infants may have an increased risk for obesity later in life, a condition associated with chronic disease. Therefore, authors have studied whether prematurely born individuals have high body fatness and consequently an increased risk for obesity later in life. However, the results of such studies show considerable variation. Stigson et al. (13) reported that prematurely born four-year-olds have a higher percentage of body fat than controls born at term. Gianni et al. (9) made similar observations with respect to five-year-old boys, although the difference between the term and preterm groups was not significant. However, Huke et al. (14) did not find any association between prematurity and increased fat mass in five- to seven-year-old children. Fewtrell et al. (15) made similar observations in children aged 8-12 years.

The variability in these results may have several explanations, for example, different gestational ages at birth or variations in the validity of the body composition method used. In this 
paper, we report the body composition of prematurely born four-year-old boys and girls. These children were born after 23.3 to 36.9 gestational weeks and were studied by means of air displacement plethysmography, which is an accurate body composition method (16).

\section{MATERIALS AND METHODS}

\section{Subjects}

Prematurely born four-year-old children were recruited through pediatric clinics in southeastern Sweden. Inclusion criteria were reasonably healthy children without malformations or serious handicaps. We recruited 188 such children, 90 girls and 98 boys. There were two sets of triplets, one of which comprised all males and one all females. Furthermore, the following twins participated in the study: 11 sets of male twins; nine sets of female twins; five sets of twins in which one was a girl and one was a boy; and one twin boy and two twin girls participating alone. The remaining children (67 boys and 62 girls) were singletons. Information about birth weight, birth length and gestational age at birth was obtained from hospital records.

We also used size and body composition data collected in 253 four-year-old controls born full-term (137 boys). At birth these children weighed $3.73 \pm 0.50 \mathrm{~kg}$ (boys) and $3.57 \pm 0.46 \mathrm{~kg}$ (girls) and they were $52 \pm 2 \mathrm{~cm}$ (boys) and $51 \pm 2 \mathrm{~cm}$ (girls) long. At four years of age 12 boys and five girls were overweight while two boys and one girl were obese. Additional descriptions of these children have been published previously (17-19).

\section{Body composition assessment}

The session started with an assessment of height to the nearest $\mathrm{cm}$ using a stadiometer. Then, body weight, volume and composition were assessed by means of the Pediatric Option of Bod Pod (Body Composition System, COSMED, Concord, CA, USA) using software 5.2.0 as 
previously described (16) and based on the Lohman body composition model (20). The volume of the child was always measured in triplicate according to the manufacturer's instructions. Fat mass index, body mass index (BMI) and fat-free mass index were calculated as fat mass (kg), body weight $(\mathrm{kg})$ and fat-free mass $(\mathrm{kg})$, respectively, each divided by length/height $\left(\mathrm{m}^{2}\right)$.

\section{Statistics}

Values given are means and standard deviations. Groups were compared using analysis of covariance, with age (days) at measurement as a covariate, followed by Tukey`s test for post hoc analyses. Linear regression analysis was used to calculate regression coefficients (slopes) and correlation coefficients (r). Multiple regression analysis was used to calculate partial r. Significance was accepted when $\mathrm{p}<0.05$. Statistical analysis was performed using Statistica software 10 (StatSoft Inc., Tulsa, OK, USA).

\section{Ethics}

The study was approved by the ethics committee in Linköping (2012/235-31, 2013/298-32). Informed consent was always obtained from one parent and, in most cases, from both parents.

\section{RESULTS}

The prematurely born boys and girls are described in Table 1. Gestational age at birth (days) correlated significantly $(\mathrm{p}<0.000001)$ with birthweight $(\mathrm{g})$ in boys $\left(\mathrm{r}^{2}=0.667\right)$ and in girls $\left(\mathrm{r}^{2}=0.747\right)$ and with length at birth $(\mathrm{cm})$ in boys $\left(\mathrm{r}^{2}=0.713\right)$ and in girls $\left(\mathrm{r}^{2}=0.712\right)$.

Prematurely born children were divided into late preterm (born after 224 days of gestation) and early preterm (born before 224 days of gestation). Table 2 shows the results obtained when these two groups were compared to each other and to controls born full-term. In 
general, prematurely born four-year-olds tended to be lighter and shorter and to contain less fat mass and fat-free mass than did full-term controls. Values for early preterm children were, in most cases, slightly lower than those for late preterm children. However, in boys, early preterm values for fat-free mass and fat-free mass index were not lower than late preterm values for those variables.

Table 3 shows the results obtained when size and body composition variables assessed at four years of age were regressed on gestational age at birth in prematurely born children. In girls, most of the size and body composition variables investigated correlated positively and significantly with gestational age at birth. However, all these relationships were relatively weak, with $\mathrm{r}^{2}$-values indicating that only 5 to $12 \%$ of the variations in height, weight, BMI, fat mass, fat mass index and fat-free mass were explained by variations in gestational age at birth. As also shown in Table 3, none of the investigated correlations were significant in boys. No significant correlation between fat-free mass index and gestational age at birth was found in boys or girls.

\section{DISCUSSION}

The $z$ scores at birth of our prematurely born children tended to be quite low. A possible explanation is that reference data by Niklasson and Albertsson-Wikland (22) were used. This reference is based on Swedish children but includes only singleton infants born to healthy mothers. Our group included triplets and twins, and we did not exclude children whose mothers suffered from hypertension or infections at the time of delivery. These conditions are often associated with premature birth (23), and hypertension during pregnancy is associated with intrauterine growth impairment (24). We consider that not excluding children of mothers with 
such conditions has made our group of children more representative of contemporary prematurely born four-year-olds.

Fewtrell et al. (15) pointed out that prematurely born children are known to remain lighter and shorter throughout childhood and adolescence. Our results are consistent with this statement but inconsistent with the results of Stigson et al. (13), who found increased body fatness in prematurely born four-year-olds. These authors used dual-energy X-ray absorptiometry to assess body composition, while we used air displacement plethysmography. Both of these methods are accurate at the group level $(16,25)$. However, Bland and Altman (26) evaluations versus a four-component reference method demonstrated that dual-energy X-ray absorptiometry may be less accurate (25) than air displacement plethysmography (16) at the individual level. Therefore, we believe that there is a risk that dual-energy X-ray absorptiometry may produce misleading results, and this risk increases in a small study. Stigson et al. (13) studied 26 children while our study included 188 children.

Our data suggest a possible sex difference regarding the effect of gestational age at birth on size and body composition variables of prematurely born four-year-olds. Thus, we observed significant relationships between gestational age at birth and most such variables in girls, while these relationships were not significant in boys. This may indicate that the last weeks of pregnancy affect the fetal development of boys and girls differently. However, it is also possible that these weeks affect both sexes in a similar way but that boys have a capacity to compensate, after birth, for adverse effects on growth and body composition development occurring during this part of pregnancy. 
Our results are in agreement with those by Huke et al. (14) and by Fewtrell et al. (15) and lend no support to the statement that prematurity is associated with an increased percentage of body fat in childhood, which would represent a risk factor for overweight and obesity. Nevertheless, this area deserves further studies. For example, Pringle et al. (27) reported that being born preterm was one factor associated with an increased obesity risk. Furthermore, we want to point out that the relationship between prematurity and chronic disease is complex and therefore it may still be relevant to consider early body composition development in prematurely born children. For example, prematurely born infants may certainly develop overweight and obesity later in childhood, and such children may possibly be more sensitive to a high body fat content than children born full-term. This possibility should be kept in mind because published evidence show that prematurity is associated with chronic disease later in life.

Strengths of this study were that we studied prematurely born children with a known and considerable variation in gestational age at birth using a valid body composition method. Limitations were that the children were recruited from southeastern Sweden only, we did not assess their body composition in infancy, and we did not investigate their energy intake or physical activity.

\section{CONCLUSION}

The body fat content of prematurely born Swedish four-year-old boys and girls was not higher than that of full-term controls. The gestational age at birth of these prematurely born children correlated positively with height, weight, BMI fat mass $(\mathrm{kg}, \%)$, fat mass index and fat-free mass in girls but not in boys. Our findings are relevant in relation to published results showing that premature birth is associated with chronic disease later in life. 


\section{ACKNOWLEDGEMENTS}

The authors thank all parents and children who participated in the study.

\section{CONFLICT OF INTEREST}

The authors declare no conflict of interest.

\section{FUNDING}

This study was supported by the Medical Research Council of Southeast Sweden. 


\section{REFERENCES}

1. Blencowe H, Cousens S, Oestergaard MZ, Chou D, Moller A-B, Narwal R, et al. National, regional, and worldwide estimates of preterm birth rates in the year 2010 with time trends since 1990 for selected countries: a systematic analysis and implications. Lancet 2012; 379: 2162-72.

2. de Jong F, Monteaux MC, van Elburg RM, Gillman MW, Belfort MB. Systemtic review and meta-analysis of preterm birth and later systolic blood pressure. Hypertension 2012; 59: 226-34.

3. Crump C, Winkleby MA, Sundquist K, Sundquist J. Risk of hypertension among young adults who were born preterm: A Swedish national study of 636,000 births. Am J Epidemiol 2011; 173: 797-803.

4. Rotteveel J, van Weissenbruch MM,Twisk JWR, Delemarre-Van de Waal HA. Infant and childhood growth patterns, insulin sensitivity, and blood pressure in prematurely born young adults. Pediatrics 2008; 122: 313-21.

5. Mathai S, Cutfield WS, Derraik JGB, Dalziel SR, Harding JE, Robinson E, et al. Insulin sensitivity and $\beta$-cell function in adults born preterm and their children. Diabetes 2012; 61: 2479-83.

6. Kaijser M, Edstedt Bonamy A-K, Akre O, Cnattingius S, Granath F, Norman M, et al. Perinatal risk factors for diabetes later in life. Diabetes 2009; 58: 523-6.

7. Hofman PL, Fiona Regan CB, Jackson WE, Jefferies C, Knight DB, Robinson EM, et al. Premature birth and later insulin resistance. N Engl J Med 2004; 35: 2179-2186. 
8. Scheurer JM, Zhang L, Gray HL, Weir K, Demerath EW, Ramel SE. Body composition trajectories from infancy to preschool in children born premature versus full-term. $J$ Pediatr Gastroenterol Nutr 2017; 64: e147-e153.

9. Gianni ML, Roggero P, Piemontese P, Morlacchi L, Bracco B, Taroni F, et al. Boys who are born preterm show a relative lack of fat-free mass at 5 years of age compared to their peers. Acta Paediatr 2015; 104:e119-e123.

10. Ramel SE, Gray HL, Ode KL, Younge N, Georgieff MK, Demerath EW. Body composition changes in preterm infants following hospital discharge: Comparison with term infants. $J$ Pediatr Gastroenterol Nutr 2011; 53: 333-8.

11. Simon L, Borrego P, Darmaun D, Legrand A, Rozé J-C, Chaunty-Frondas A. Effect of sex and gestational age on neonatal body composition. Br J Nutr 2013; 109: 1105-8.

12. Johnson MJ, Wootton SA, Leaf AA, Jackson AA. Preterm birth and body composition at term equivalent age: A systematic review and meta-analysis. Pediatrics 2012; 130: e640-e649.

13. Stigson L, Kistner A, Sigurdsson J, Engström E, Magnusson P, Hellström A, et al. Bone and fat mass in relation to postnatal levels of insulin-like growth factors in prematurely born children at $4 \mathrm{y}$ of age. Pediatr Res 2014; 75: 544-50.

14. Huke V, Rudloff S, Brugger M, Strauch K, Berthold LD, Landmann E. Prematurity is not associated with intra-abdominal adiposity in 5- to 7-year-old children. $J$ Pediatr 2013; 163 : $1301-6$.

15. Fewtrell MS, Lucas A, Cole TJ, Wells JCK. Prematurity and reduced body fatness at 8-12 y of age. Am J Clin Nutr 2004; 80: 436-40. 
16. Fields DA, Allison DB. Air-displacement plethysmography pediatric option in 2-6 years old using the 4-compartment model as a criterion method. Obesity (Silver Spring) 2012; 20: 1732-7.

17. Henriksson P, Löf M, Forsum E. Parental fat-free mass is related to the fat-free mass of infants and maternal fat mass is related to the fat mass of infant girls. Acta Paediatr 2015; 104 : $491-7$.

18. Forsum E, Eriksson B, Flinke E, Henriksson H, Henriksson P, Löf M. Fat and fat-free mass of healthy Swedish children show tracking during early life, but there are differences. Acta Paediatr 2019; in press.

19. Eriksson B, Löf M, Forsum E. Body composition in full-term healthy infants measured with air displacement plethysmography at 1 and 12 weeks of age. Acta Paediatr 2010; 99:563-8.

20. Lohman TG. Assessment of body composition in children. Pediatr Exerc Sci 1989; 1: 19-30.

21. Cole TJ, Bellizzi MC, Flegal KM, Dietz WH. Establishing a standard definition for child overweight and obesity worldwide: international survey. Br Med J 2000; 320: 1240-3.

22. Niklasson A, Albertsson-Wikland K. Continuous growth reference from $24^{\text {th }}$ week of gestation to 24 months by gender. BMC Pediatrics 2008, 8:8, doi:10.1186/1471-2431-8-8.

23. Goldenberg RL, Culhane JF, Iams JD, Romero R. Epidemiology and causes of preterm birth. Lancet 2008; 371:75-84.

24. American College of Obstetricians and Gynecologists Task Force. Hypertension in Pregnancy. Obstet Gynecol 2013; 122: 1122-31. 
25. Wells JCK, Fuller NJ, Dewit O, Fewtrell MS, Elia M, Cole TJ. Four-component model of body composition in children: density and hydration of fat-free mass and comparison with simpler models. Am J Clin Nutr 1999; 69: 904-12.

26. Bland JM, Altman DG. Statistical methods for assessing agreement between two methods of clinical measurement. Lancet 1986; 1: 307-10.

27. Pringle KG, Lee YQ, Weatherall L, Keogh L, Diehm C, Roberts CT, et al. Influence of maternal adiposity, preterm birth and birth weight centiles on early childhood obesity in an indigenous Australian pregnancy-through-to-early-childhood cohort study. J Dev Orig Health Dis 2019; 10: 39-47. 
Table 1 Description of prematurely born girls and boys in the study. Values are means \pm standard deviations.

At birth

- Gestational age (days)

- Weight (g)

- Weight $z$ score

- Length $(\mathrm{cm})$

- Length $z$ score

At four years of age

- Age at measurement (days)

- Weight $(\mathrm{kg})$

- Height (cm)

- Body mass index $\left(\mathrm{kg} / \mathrm{m}^{2}\right)$

- Fat mass (kg)

- $\quad$ Fat mass (\%)

- Fat mass index $\left(\mathrm{kg} / \mathrm{m}^{2}\right)$

- Fat-free mass $(\mathrm{kg})$

- Fat-free mass index $\left(\mathrm{kg} / \mathrm{m}^{2}\right)$
Girls ( $\mathrm{n}=90)$

$$
222 \pm 24^{*}
$$

$1710 \pm 640$

$-0.93 \pm 1.42$

$41 \pm 5$

$-1.02 \pm 2.01$

$1621 \pm 22$

$16.6 \pm 2.5$

$105 \pm 5$

$15.1 \pm 1.4^{\ddagger}$

$4.5 \pm 1.5$

$26.5 \pm 6.1$

$4.06 \pm 1.19$

$12.1 \pm 1.5$

$11.0 \pm 0.8$
Boys $(\mathrm{n}=98)$

$$
230 \pm 22^{+}
$$

$2053 \pm 656$

$-0.65 \pm 1.36$

$44 \pm 5$

$-0.54 \pm 1.69$ 
Table 2 Size and body composition variables of full-term and preterm girls and boys at four years of age. Prematurely born children were divided into late preterm (born after $>224$ days of gestation) and early preterm (born after $<224$ days of gestation). Values are means \pm standard deviations*

G i r 1 s

\section{Full-term $\quad$ Late preterm}

$(n=116)$

$(n=49)$

Weight (kg)

Height (cm)

Body mass index

$17.9 \pm 2.0^{+}$

$107 \pm 4^{+\S}$

$15.6 \pm 1.2^{\ddagger}$

$$
17.1 \pm 2.5
$$

$105 \pm 6$

$15.4 \pm 1.3$

$\left(\mathrm{kg} / \mathrm{m}^{2}\right)$

Fat mass (kg)

Fat mass (\%)

Fat mass index $\left(\mathrm{kg} / \mathrm{m}^{2}\right)$

Fat-free mass (kg)

Continued
B o y $\mathrm{s}$

Early preterm

Full-term

Late preterm

Early preterm

$(n=41)$

$(n=137)$

$(n=66)$

$(n=32)$

$16.0 \pm 2.2$

$18.7 \pm 2.3^{\dagger}$

$17.8 \pm 2.2$

$17.5 \pm 1.8^{\S}$

$104 \pm 4$

$109 \pm 4^{+}$

$107 \pm 4$

$106 \pm 3^{\S}$

$14.8 \pm 1.4$

$15.8 \pm 1.3$

$15.6 \pm 1.4$

$15.6 \pm 1.1$

$\begin{array}{ll}.8 \pm 1.5 & 4.1 \pm 1.4^{\S} \\ 27.6 \pm 5.7 & 25.3 \pm 6.5 \\ .29 \pm 1.16^{\ddagger} & 3.78 \pm 1.17 \\ 2.3 \pm 1.6 & 11.9 \pm 1.4\end{array}$

$4.7 \pm 1.0$

$4.5 \pm 1.2$

$4.2 \pm 0.8$

$25.1 \pm 4.1$

$25.3 \pm 4.6$

$23.7 \pm 3.5$

$3.98 \pm 0.80$

$3.96 \pm 0.96$

$3.71 \pm 0.67$

$14.0 \pm 1.9^{\S}$

$13.3 \pm 1.5$

$13.4 \pm 1.4$ 
Table 2, continued

Fat-free mass index

$11.2 \pm 0.9$

$11.1 \pm 0.8$

$11.0 \pm 0.9$

$11.8 \pm 1.0$

$11.6 \pm 0.9$

$11.9 \pm 0.9$

$\left(\mathrm{kg} / \mathrm{m}^{2}\right)$

* Groups were compared using analysis of covariance, with age (days) at measurement as a covariate, followed by Tukey`s test for post hoc analyses.

${ }^{+}$Significantly different from the corresponding value for early preterm children of the same $\operatorname{sex}(\mathrm{p}<0.001)$

Significantly different from the corresponding value for early preterm children of the same $\operatorname{sex}(p<0.05)$

$\S$ Significantly different from the corresponding value for late preterm children of the same $\operatorname{sex}(\mathrm{p}<0.05)$ 
Table 3 Size and body composition variables, assessed at four years of age, regressed on gestational age at birth in prematurely born boys and girls. The table shows regression coefficients (slope*) and $\mathrm{r}^{2}$-values based on partial correlation coefficients $\left(\mathrm{r}^{+}\right)$.

\begin{tabular}{|c|c|c|c|c|}
\hline & \multicolumn{2}{|c|}{ Girls $(\mathrm{n}=90)$} & \multicolumn{2}{|c|}{ Boys $(\mathrm{n}=98)$} \\
\hline Dependent variable & Slope & $r^{2}(p$ value $)$ & Slope & $r^{2}(p$ value $)$ \\
\hline Height (cm) & 0.0502 & $0.065(0.016)$ & 0.0261 & $0.019(>0.05)$ \\
\hline Weight (kg) & 0.0331 & $0.117(0.001)$ & 0.0060 & $0.005(>0.05)$ \\
\hline Body mass index $\left(\mathrm{kg} / \mathrm{m}^{2}\right)$ & 0.0155 & $0.083(0.006)$ & -0.0026 & $0.001(>0.05)$ \\
\hline Fat mass (kg) & 0.0177 & $0.089(0.004)$ & 0.0060 & $0.018(>0.05)$ \\
\hline Fat mass $(\%)$ & 0.0574 & $0.051(0.033)$ & 0.0244 & $0.020 \quad(>0.05)$ \\
\hline Fat mass index $\left(\mathrm{kg} / \mathrm{m}^{2}\right)$ & 0.0122 & $0.064(0.017)$ & 0.0033 & $0.010(>0.05)$ \\
\hline Fat-free mass (kg) & 0.0155 & $0.074(0.010)$ & -0.0001 & $0.000(>0.05)$ \\
\hline Fat-free mass index $\left(\mathrm{kg} / \mathrm{m}^{2}\right)$ & 0.0033 & $0.012(>0.05)$ & -0.0059 & $0.019(>0.05)$ \\
\hline
\end{tabular}

Continued 
Table 3, continued

* Calculated as the dependent variable divided by gestational age at birth (days)

${ }^{+}$Partial correlation coefficients adjusted for age (days) at measurement. 


\section{APPENDIX S1}

The body composition study group

- Ingela Danielsson MD; Children's Hospital, Linköping University Hospital, Linköping, Sweden

- Fredrik Ingemansson MD; Pediatric Department, Ryhov County Hospital, Jönköping, Sweden

- Anders Palm MD; Pediatric Clinic, Västervik Hospital, Västervik, Sweden

- Erik Wejryd MD; Department of Pediatrics, Vrinnevi Hospital, Norrköping, Sweden 